\title{
Effects of the Distance between Renal Calculi and Skin and the Body Mass Index on the Success of ESWL among Renal Calculi Patients
}

\author{
Bulent Kati*, Eyyup Sabri Pelit, Ismail Yagmur, Suleyman Sagir, Halil Ciftci and Ercan Yeni \\ Department of Urology, Harran University, Sanliurfa, Turkey
}

Submission: May 05, 2017; Published: June 30, 2017

*Corresponding author: Bulent Kati, Assistant Professor of Urology, Department of Urology, Harran University, Sanliurfa, Turkey, Tel: +90-414-318 30 00/+90-505-3081350; Fax: +90-414-3444444; Email: bulentkati@harran.edu.tr

\begin{abstract}
Objective: Extracorporeal shock wave lithotripsy (ESWL) took the first place among the noninvasive calculi treatments after observing its effects on the renal calculi. In this study, it was aimed to reveal the effects of patient's body mass index and distance between skin and stone on the success of ESWL treatment.
\end{abstract}

Material and methods: The patients, who applied to our Urology Clinic between December 2015 and December 2016, who was diagnosed for renal calculi, who had non-sub kidney and $0.5-1.5 \mathrm{~cm}$ stones and for whom the ESWL treatment was planned, were involved in this study. Using the recorded heights and weights of the patients, the body mass indices were calculated. After the ESWL treatment, the shortest distance between skin and stone was determined using computed tomography and/or ultrasound.

Results: Among 72 patients, for whom the ESWL was applied, Mean age was calculated to be $41.1 \pm 14.3$ years. Mean size of the stones was found to be $1.3 \pm 0.4 \mathrm{~cm}$. Mean body mass index of the patients was calculated to be $25.6 \pm 4.7 \mathrm{~kg} / \mathrm{m}^{2}$. Mean distance between skin and stone, which was measured using ultrasound, was $7.2 \pm 1.6 \mathrm{~cm}$. After first session of ESWL, 54 patients $(75 \%)$ were considered successful as a result of appropriate hydration and medical treatment.

Conclusion: Although the distance between skin and stone was considered to be successful in treatment's success, the BMI of patients showed no significant effect. The success of ESWL treatment depends on many factors, and it is more appropriate to assess the success of treatment independently for each of patients.

Keywords: Renal calculi; Shock wave lithotripsy; Calculi treatment

Abbreviations: ESWL: Extracorporeal Shock Wave Lithotripsy; SSD: Skin-Stone Distance; BMI: Body Mass Index

\section{Introduction}

The lithiasis developing in the urinary system is the problem that is most frequently seen in urology, following the urinary system infections and prostate-related problems [1]. Extracorporeal Shock wave lithotripsy (ESWL) is one of the noninvasive treatment methods that is still being used for noncomplicated stones [2]. Especially for the cases with single stone, the success of this treatment option reaches up to $80-85 \%$, and it saves the patients from surgical risks [3]. Many factors such as the size, structure, an localization of stone are the stone-related reasons influencing the success of ESWL, and the patientrelated factors also affect the success of this treatment [4].
When compared to surgical methods, it has certain advantages such as shorter time of hospitalization, faster healing, lower complication rates, and repeatability [5]. Moreover, the shock waves applied have also potential to cause the hemorrhage in thin-walled veins of kidney and adjacent tissues, the perinephric hematoma, the bacteremia, the urinary system obstruction caused from the stone fragments, and the cardiac complications [6]. In previous studies, the depth of stone within the body was shown to be capably of affecting the effects of shock waves $[7,8]$. In this study, where we applied ESWL on adult patients, we aimed to examine the effects of skin-stone distance (SSD) and body mass index (BMI) on the treatment results. 


\section{Subjects and Methods}

In this study, 73 patients, who were hospitalized in Urology Clinic of our university medical faculty Hospital between December 2015 and December 2016, having renal-located 0.5$1.5 \mathrm{~cm}$ stones (not in lower pole) and older than 18 year-old were involved. After ethics committee and patient approval, the data of 73 patients, who have never been undergone to any treatment for stone, were retrospectively examined. Ureteral stent was not placed on none of the patients, and no severe complication developed following the process.

Urinary culture was performed for each of the patients, and ESWL was performed for sterile ones. Only the renal stones were involved in this study, and there was no difference in terms of the stone loads. Since it is a factor affecting the success of ESWL, the patients with sub-kidney pole stones and those having stone in ureter were not involved in the present study. All of the patients were treated with ESWL using shock wave between 1500 and 3000 and energy between 12 and $21 \mathrm{kV}$.
The lithotripsy procedure was performed using Elmed (Elmed Medical Systems Multimed Classic/Turkey) in urology clinic of our university hospital. At the same time, the shortest skin-stone distance was measured using ultrasound connected to ESWL device, and the stone was focus (Figure 1a-1b). The heights and weights of patients were recorded. BMI values of the patients were calculated by dividing the square of patient height expressed in meter to the weight of patient expressed in kilogram. As a routine, by applying non-steroid antiinflammatory, analgesic, and diuretic, the excessive hydration and mobilization were recommended. Alfa-blocker or calcium canal blocker was not utilized. 5 days before the ESWL session, the rate of absence of stone was determined using direct graph and USG and also unenhanced computed tomography in order to ensure the accuracy. The stones smaller than $3 \mathrm{~mm}$, which doesn't cause any symptom, and the absence of stone except for the clinically unimportant fragments were considered successful. Mean SSD and BMI values were calculated separately for successful cases.

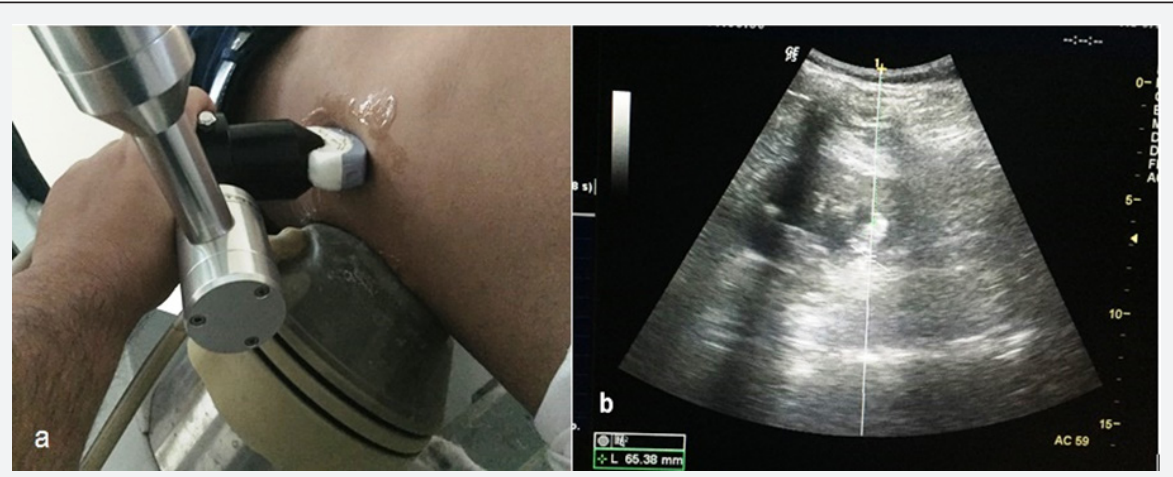

Figure 1a-1b: Focusing on the stone via ultrasound and measuring the skin-stone distance.

For the descriptive statistics, the mean values, standard deviation, median, minimum and maximum value frequencies and percentage were utilized. The distribution of variables was examined using Kolmogorov-Smirnov test. For comparing the quantitative data, the Independent Samples t Test and MannWhitney U test were employed. For comparison of qualitative data, the Chi-Square test was used. SPSS 22.0 version was used in statistical analyses.

Table 1: General information of participating patients and the treatment status.

\begin{tabular}{|c|c|c|c|c|c|c|}
\hline & & Min & Max & Median & Mean $\pm S . D$. & n- $\%$ \\
\hline Age & & 18 & 85,0 & 40,0 & $41,1 \pm 14,3$ & \\
\hline \multirow{2}{*}{ Gender } & Female & & & & 21 & $29.20 \%$ \\
\hline & Male & & & & 51 & $70.80 \%$ \\
\hline Weight & & 45 & 105 & 75 & $75.6 \pm 14.1$ & \\
\hline Length & & 1.6 & 1.9 & 1.7 & $1.7 \pm 0.1$ & \\
\hline BMI & & 15.8 & 37.6 & 25.4 & $25.6 \pm 4.7$ & \\
\hline $\mathrm{SSD}(\mathrm{Cm})$ & & 4.3 & 11.8 & 6.9 & $7.2 \pm 1.6$ & \\
\hline Stone Size $(\mathrm{Cm})$ & & 0.8 & 2 & 1.3 & $1.3 \pm 0.4$ & \\
\hline Un-Succes & & & & & 18 & $25 \%$ \\
\hline Succes & & & & & 54 & $75 \%$ \\
\hline
\end{tabular}

Among 72 patients, for whom the ESWL was applied, 51 were male and 21 were female. Mean age was $41.1 \pm 14.3$ years. Mean size of stones was found to be $1.3 \pm 0.4 \mathrm{~cm}$. Mean BMI value of the patients was determined to be $25.6 \pm 4.7 \mathrm{~kg} / \mathrm{m}^{2}$. Mean skin-stone distance measured in ultrasound was found to be $7.2 \pm 1.6 \mathrm{~cm}$ (Table 1). 
Together with the appropriate hydration and medical treatment, the treatment was determined to be successful in 54 patients $(74.9 \%)$ following the first session of ESWL. And then, after observing the absence of stone in 6 patients following $2^{\text {nd }}$ and $3^{\text {rd }}$ sessions of ESWL, it was found that the treatment was successfully implemented in 60 patients $(82.1 \%)$. Mean skinstone distance for the patients treated with first session of ESWL was found to be $6.8 \pm 0.45 \mathrm{~cm}$, while BMI was calculated to be $25.6 \pm 1$. Following the treatment, gross hematuria developed in 5 patients (6.8\%), while endoscopic intervention was performed for 2 patients $(2.7 \%)$ due to the calculi.

Among the patients, for whom the ESWL treatment was successful, and those with unsuccessful treatment, the age, gender distribution, height, weight, and BMI values showed statistically non-significant difference $(p>0.05)$. The SSD value of successful group was statistically significantly lower than that of unsuccessful group $(\mathrm{p}<0.05)$. The stone size didn't statistically significantly differ between the successful and unsuccessful groups ( $p>0.05$ ) (Table 2).

Table 2: Statistical analysis of patients receiving ESWL treatment (tt test / mMann-whitney u test / $\mathrm{X}^{2} \mathrm{Chi}$-square test).

\begin{tabular}{|c|c|c|c|c|c|c|c|c|}
\hline & & Un-success & & & Success & & & \\
\hline & & Mean \pm S.D & n- $\%$ & Median & Mean $\pm S . D$ & n- $\%$ & Median & p \\
\hline Age & & $45.3 \pm 16.3$ & & 42.5 & $39.7 \pm 13.4$ & & 38.5 & $0.152 t$ \\
\hline \multirow{2}{*}{ Gender } & Female & 5 & $27.80 \%$ & & 16 & $29.6 \%$ & & $0,881 X^{2}$ \\
\hline & Male & 13 & $72.20 \%$ & & 38 & $70.4 \%$ & & \\
\hline Weight & & $80.1 \pm 13.0$ & & 84 & $74.0 \pm 14.2$ & & 75 & $0.113^{t}$ \\
\hline Length & & $1.7 \pm 0.1$ & & 1.8 & $1.7 \pm 0.1$ & & 1.7 & $0.299^{t}$ \\
\hline BMI & & $26.6 \pm 4.3$ & & 27.1 & $25.2 \pm 4.9$ & & 24.5 & $0.273^{t}$ \\
\hline $\mathrm{SSD}(\mathrm{cm})$ & & $7.9 \pm 1.6$ & & 7.5 & $6.9 \pm 1.6$ & & 6.5 & $0.024^{\mathrm{m}}$ \\
\hline $\begin{array}{l}\text { Stone Size } \\
(\mathrm{cm})\end{array}$ & & $1.4 \pm 0.4$ & & 1.4 & $1.3 \pm 0.3$ & & 1.3 & $0.621^{\mathrm{m}}$ \\
\hline
\end{tabular}

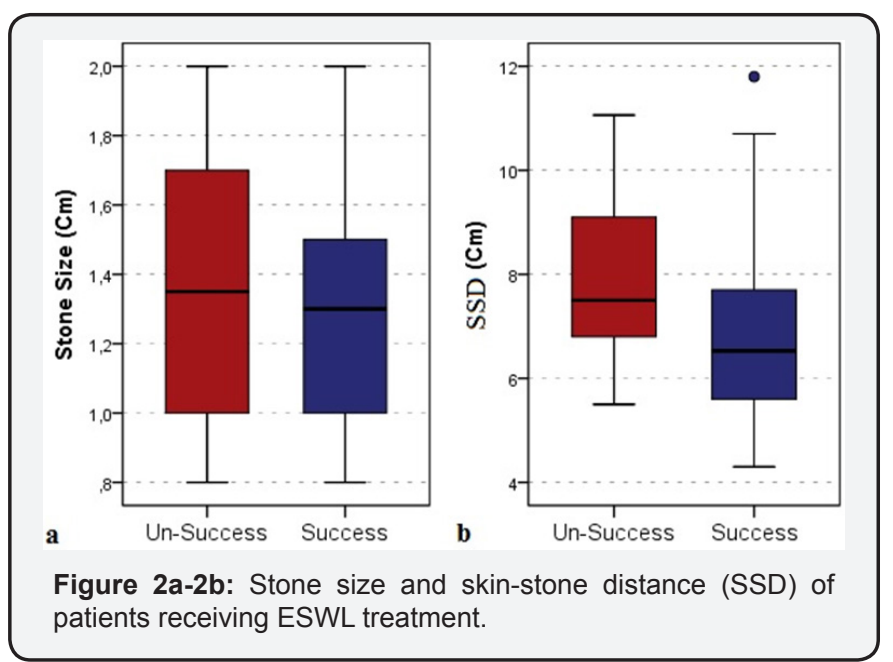

\section{Discussion}

Together with the use of ESWL in treating the urinary lithiasis, a revolution decreasing the morbidity and mortality was experienced [9]. Even though the success of this treatment varied among the studies, it generally ranges between 60 and $95 \%$, and many factors might influence this low rate of success. Main ones among these factors are large size of stone, calix stones that are difficult to pass, structure of stone, and obesity [10]. In the present study, we minimized the differences and employed the adult patients with similar size and location of stones, and examined the effects of BMI and skin-stone distance on the success of ESWL treatment.
Since 1990s, Word Health Organization has been recommending Body Mass Index (BMI) for the classification of individuals in terms of the obesity. In this method, where the value is calculated by dividing the square of patient height expressed in meter to the weight of patient expressed in kilogram, the values between 19 and $24 \mathrm{~kg} / \mathrm{m}^{2}$ are considered to be normal, those between 25 and $29 \mathrm{~kg} / \mathrm{m}^{2}$ to be overweight, those between 30 and $35 \mathrm{~kg} / \mathrm{m}^{2}$ to be 1 st level obese, those between 35 and $40 \mathrm{~kg} / \mathrm{m}^{2}$ to be $2^{\text {nd }}$ level obese, and those higher than $40 \mathrm{~kg} / \mathrm{m}^{2}$ to be morbid obese. Mean BMI value of patients in present study was found to be $25.6 \pm 4.7$ and this indicates that the patients passed beyond the upper level of normal range. In study of Akay et al. [10] the body fat index and body fat mass were examined together with BMI and it was found that these values had significant role in success of ESWL treatment.

In study of Dede et al. [11] it was reported that, since the morbidity and mortality of obese patients were high, ESWL was an efficient method in treating the upper edge ureter stones. Nussberger et al. [12] in their study, emphasized that ESWL increased the risk of hematoma and renal defect in patients with BMI lower than $21.5 \mathrm{~kg} / \mathrm{m}^{2}$ and higher than $30 \mathrm{~kg} / \mathrm{m}^{2}$. In the present study, gross hematuria developed in 5 patients, and only 2 of them were within the ranges considered to be risky. In ESWL study of Akça $O$ et al. on pediatric patient group, they reported that ESWL might not have any disadvantage among the children [13]. Similarly, in study of Hatiboglu et al. [14] when the use of new generation lithotripter was utilized, BMI was reported to have no effect among the prognostic variables thought to 
play role in success of ESWL. In our study, we determined that BMI didn't significantly affect the success or failure of ESWL treatment.

Skin-stone distance was used in assessing the success of ESWL in many studies. Pareek et al. [15] found that, after evaluation of ESWL patients with lower pole kidney stones measuring 0.5 to $1.5 \mathrm{~cm}$ on CT, the SSD may predict the outcome after treatment. They reported that SSD is effective in success of ESWL especially for the lower pole stones, and that it increased the failure rate in cases with $>10 \mathrm{~cm}$ stones. In our study, we measured the SSD as the shortest distance by utilizing USG connected to our ESWL device and automatically focusing. Since CT is not a part of our routine protocol for every lithiasis patient, we checked these distances separately for patients, CT of whom were taken. In order to reveal the diameter and angle of infundibulum, the lower pole stones were not used in our study and only the renal pelvis, medial and upper pole stones were involved [16].

Moreover, mean SSD size of the patients in our study was found to be $7.2 \pm 1.6 \mathrm{~cm}$, this was calculated to be $6.9 \pm 1.6 \mathrm{~cm}$ for those considered to be successful in ESWL treatment, and this parameter was observed to be significantly effective $(p<0.05)$. In study of Jacobs et al. [17] the authors asserted that skinstone distance did not have statistically significant effect on the success of ESWL treatment, that the stabilization of all the factors that might be effective in treatment was very difficult, and that the further studies were needed. As it was attempted to show in many study, BMI and SSD are among the most important parameters thought to potentially influence the success of ESWL treatment. However, many independent factors, which might be different in each patient, such as stone size and structure, anatomic structure of urinary system, technological infrastructure of lithotripter in use, experience of technician/ physician implementing the treatment, medical treatment used for passing the stone after treatment and personal efforts play role.

\section{Conclusion}

As well as ESWL might be successfully used in noninvasive lithiasis therapies, we observed in our study that BMI had statistically non-significant effect on the patients receiving ESWL treatment but SSD significantly influenced the success of treatment. But, since there are many individual factors influencing the success of therapy, we believe that each of the stones and patients should be separately examined and the treatment for them should be individually determined.

\section{References}

1. Stoller MI, Bolton DM (2000) Urinary Stone Disease, Smith's Generaly Urology San Fancisco, USA, pp. 291-320.

2. Lingeman JE, McAteer JA, Gnessin E, Evan AP (2009) Shock wave lithotripsy: Advances in technology and technique. Nat Rev Urol 6(12): 660-670.
3. Paterson RF, Lifshitz DA, Kuo RL, Siqueira TM , Lingeman JE (2002) Shock wave lithotripsy monotherapy for renal calculi. Int Braz J Urol 28(4): 291-301.

4. Turk C, Knoll T, Petrik A, Sarica K, Skolarikos A, et al. (2015) EAU Urolithiasis Guidelines.

5. Logarakis NF, Jewett MAS, Luymes J, Honey RJ (2000) Variation in clinical outcome folowing shock wave lithotripsy. J Urol 163(3): 721725 .

6. Skolarikos A, Alivizatos G, de la Rosette J (2006) Extracorporeal shock wave lithotripsy 25 years later: Complication sand their prevention. Eur Urol 50(5): 981-990.

7. Miller NL, Lingeman JE (2007) Management of kidney stones. BMJ 334: 468-72.

8. Tan YM, Yip SK, Chong TW, Wong MY, Cheng C, et al. (2002) Clinical experience and results of ESWL treatment for 3,093 urinary calculi with the Storz Modulith SL 20 lithotripter at the Singapore general hospital. Scand J Urol Nephrol 36(5): 363-367.

9. Deurenberg P, Yap M (1999) The assessment of obesity: methods for measuring body fat and global prevalence of obesity. Baillieres Best Pract Res Clin Endocrinol Metab 13(1): 1-11.

10. Akay AF, Gedik A, Tutus A, Sahin H, Bircan MK (2007) Body mass index, body fat percentage, and the effect of body fat mass on SWL success. Int Urol Nephrol 39(3): 727-730.

11. Dede O, Şener NC, Baş O, Dede G, Bağbancı MŞ (2015) Does morbid obesity influence the success and complication rates of extracorporeal shock wave lithotripsy for upper ureteral stones? Turk J Urol 41(1): 20-23.

12. Nussberger F, Roth B, Metzger T, Kiss B, Thalmann GN, et al. (2016) A low or high BMI is a risk factor for renal hematoma after extracorporeal shock wave lithotripsy for kidney stones. Urolithiasis 45(3): 317-321.

13. Akça O, Horuz R, Boz MY, Kafkasli A, Gökhan O, Göktaş C, et al. (2013) Obesity might not be a disadvantage for SWL treatment in children with renal stone. Int Urol Nephrol 45(1): 11-16.

14. Hatiboglu G, Popeneciu V, Kurosch M, Huber J, Pahernik S, et al. (2011) Prognostic variables for shock wave lithotripsy (SWL) treatment success: noimpact of body mass index (BMI) using a third generation lithotripter. BJU Int 108(7): 1192-11977.

15. Pareek G, Hedican SP, Lee FT, Nakada SY (2005) Shock wave lithotripsy success determined by skin-to-stone distance on computed tomography. Urology 66(5): 941-944.

16. Gunlüsoy B, Degirmenci T, Yener H, Nergiz N, Minareci S, et al. (2005) The impact of infundibulopelvic anatomy and angle on stone clerance of isolated lower pole stones after extracorporeal shock wave lithotripsi. Turk J Urol 31: 240-5.

17. Jacobs BL, Smaldone MC, Smaldone AM, Ricchiuti DJ, Averch TD (2008) Effect of skin-to-stone distance on shockwave lithotripsy success. J Endourol 22(8): 1623-1627. 


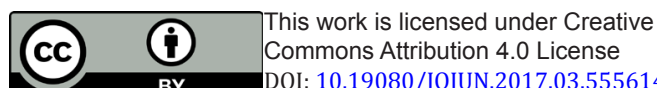

BY DOI: 10.19080/JOJUN.2017.03.555614

\section{Your next submission with Juniper Publishers} will reach you the below assets

- Quality Editorial service

- Swift Peer Review

- Reprints availability

- E-prints Service

- Manuscript Podcast for convenient understanding

- Global attainment for your research

- Manuscript accessibility in different formats

( Pdf, E-pub, Full Text, Audio)

- Unceasing customer service

Track the below URL for one-step submission https://juniperpublishers.com/online-submission.php 